\title{
Characteristics of flavored and non-flavored waterpipe tobacco users: a real-world setting study
}

\author{
Mohammad Ebrahimi Kalan ${ }^{1} \cdot$ Malek Abazari ${ }^{2} \cdot$ Ziyad Ben Taleb $^{3} \cdot$ Davoud Adham $^{2} \cdot$ Abbas Abbasi $^{2} \cdot$ Zoran Bursac $^{4}$. \\ Kenneth D Ward ${ }^{5} \cdot{\text { Caroline O } \text { Cobb }^{6} \cdot \text { Raed Behaleh }^{7} \cdot \text { Heather Lynn Wipfli }}^{8} \cdot$ Mehdi Fazlzadeh $^{9}$ (I)
}

Received: 6 February 2021 / Accepted: 31 May 2021 / Published online: 5 June 2021

(C) The Author(s), under exclusive licence to Springer-Verlag GmbH Germany, part of Springer Nature 2021

\begin{abstract}
We aimed to compare sociodemographic characteristics, smoking patterns, beliefs and perceptions, nicotine dependence, and psychological indicators between flavored waterpipe (WP) tobacco (FWT) and non-flavored WP tobacco (non-FWT) smokers in Iran. A cross-sectional study was conducted in 94 WP-serving venues surrounding Tehran and Ardabil metropolitans in Iran. Convenience sampling was applied to select 900 current WP smokers [508 (56\%) FWT-only and 392 (44\%) non-FWT-only smokers] aged 18 years and older. Multivariable logistic regression was used to examine the independent characteristics of FWT and non-FWT smokers. Compared to non-FWT smokers, FWT smokers were younger (adjusted odds ratio $[\mathrm{AOR}]=0.88,95 \%$ confidence interval [CI]: 0.87-0.90) and more likely to have $\geq 1$ sibling who smoked WP (AOR=1.54, 95\% CI: 1.06-2.24), share WP with others ( $\mathrm{AOR}=2.52,95 \% \mathrm{CI}: 1.68-3.77)$, report current cigarette smoking (AOR=2.05, 95\% CI: 1.23-3.42), and report confidence in quitting at any time (AOR=3.64, 95\% CI: $2.45-5.39)$. FWT smokers were less likely to have seen (AOR=0.40, 95\% CI: $0.27-0.60$ ) or read (AOR=0.44, 95\% CI: 0.24-0.80) warning messages on WP tobacco packages relative to non-FTW smokers. The most common self-reported reason for smoking WP was entertainment for both groups, followed by stress relief for non-FWT smokers and the escape from loneliness for FWT smokers. FWT-only smokers differ from non-FWT-only smokers in several aspects including being younger, having more positive beliefs and perceptions regarding WP use, and having higher cigarette smoking prevalence. These findings will help in developing more effective and targeted policies and cessation interventions for WP smokers according to flavor type they use, especially in the Middle East.
\end{abstract}

Keywords Flavor $\cdot$ Waterpipe $\cdot$ Hookah $\cdot$ Galyan · Tobacco $\cdot$ Smoking $\cdot$ Iran

Responsible Editor: Philippe Garrigues

Davoud Adham

d.aham@arums.ac.ir

Mehdi Fazlzadeh

M.fazlzadeh@arums.ac.ir; m.fazlzadeh@gmail.com

1 Department of Epidemiology, Robert Stempel College of Public Health, Florida International University, Miami, FL, USA

2 Department of Public Health, School of Health, Ardabil University of Medical Sciences, Daneshgah St, Ardabil 5615731567, Iran

3 Department of Kinesiology, College of Nursing and Health Innovation, University of Texas at Arlington, Arlington, TX, USA

4 Department of Biostatistics, Robert Stempel College of Public Health, Florida International University, Miami, FL, USA
5 School of Public Health, University of Memphis, Memphis, TN, USA

6 Department of Psychology, Virginia Commonwealth University, Richmond, VA, USA

7 School of Health Sciences, Baldwin Wallace University, Berea, OH, USA

8 Keck School of Medicine, University of Southern California, Los Angeles, CA, USA

9 Social Determinants of Health Research Center, Ardabil University of Medical Sciences, Ardabil, Iran 


\section{Introduction}

Tobacco use continues to be the cause of about 8 million preventable deaths annually around the globe (World Health Organization 2019). One of the contributors to this burden is waterpipe (WP; aka Hookah, Shisha, and Qalyān) tobacco smoking (Maziak et al. 2015). In many Middle Eastern countries, WP tobacco is usually marketed in two forms: dry nonflavored WP tobacco (non-FWT; known locally as Ajami or Tumbak) and moist flavored WP tobacco (FWT; ma'assel), which is infused with honey syrup, sweeteners, and a variety of flavors (Fig. 1) (Bou Fakhreddine et al. 2014; Qasim et al. 2019). Non-FWT smoking goes back to the sixteenth century in India and Persia typically produces strong, harsh smoke which has historically limited its use to older men, who often gather to smoke WP in cafés, where they visit with friends and drink tea (Bou Fakhreddine et al. 2014; Maziak et al. 2015). The addition of a variety of flavors to WP tobacco (ma'assel; molasses-soaked tobacco) was introduced in the early 1990s, resulting in smoother and more aromatic smoke, which initially attracted young people in the Middle East and, subsequently, young people worldwide, to WP smoking (Jawad and Roderick 2017). FWT is now a primary reason WP smokers cite for smoking initiation and sustained use which drives the global WP epidemic, especially among young people (Villanti et al. 2017).

All forms of tobacco, whether flavored or not, are harmful. Despite well-established evidence showing that WP tobacco smoking is associated with many adverse health outcomes, such as impaired lung function, cardiorespiratory illnesses, cancer, and nicotine dependence (ElZaatari et al. 2015; Hawari et al. 2013; Mamtani et al. 2017). Many smokers erroneously perceive WP tobacco smoking to be less harmful and addictive than smoking cigarettes (Maziak et al. 2004a). This misconception is driven in part by the [false] belief that water filtration reduces exposure to harmful constitutes in tobacco smoke and in part by the fact that flavor-infused sweetened tobacco masks the harsh sensations of smoking often experienced with other tobacco products (Alvur et al. 2014). Previous studies done by our team (Fazlzadeh et al. 2015; Heydari et al. 2019; Naddafi et al. 2019a; Naddafi et al. 2019b; Rostami et al. 2021; Rostami et al. 2020; Rostami et al. 2019) reported higher concentrations of particular matter, polycyclic aromatic hydrocarbons, carbon monoxide, aldehydes, and heavy metal emission sources in the indoor air of FWT-serving venues, as compared with those serving non-FWT-only. The findings from environmental and laboratory studies highlight the importance of investigating characteristics of FWT and non-FWT smokers in order to curb WP smoking epidemic, especially among youngsters.

While FWT is the predominant form of WP tobacco used worldwide, non-FWT continues to be used throughout the Middle East. To date, we are unaware of any studies comparing the characteristics of WP smokers who use non-FWT to those who use FWT. A limited number of studies have compared the impact of FWT and non-FWT on smoking behavior, subjective experiences, and toxicant exposure among WP smokers in controlled laboratory settings (Ben Taleb et al. 2019b; Leavens et al. 2018). However, FWT and non-FWT users may differ in important characteristics that have not yet been investigated in real-world settings. Consequently, to fill this gap, the present study surveyed FWT-only and non-FWT-only smokers recruited from cafes in two cities in Iran to compare characteristics, smoking patterns, beliefs, and perceptions about WP tobacco smoking, nicotine dependence, and psychological indicators. Data on the factors associated with the use of non-FWT and FWT is needed to develop comprehensive approaches to curb the use of WP in countries where both types of tobacco products are smoked.
Fig. 1 Typical flavored (panel A) and non-flavored (panel B) waterpipe tobacco used in Iran. Retrieved from https://www. alhamraco.com/Product and http://cyrusgallery.ir/product
A

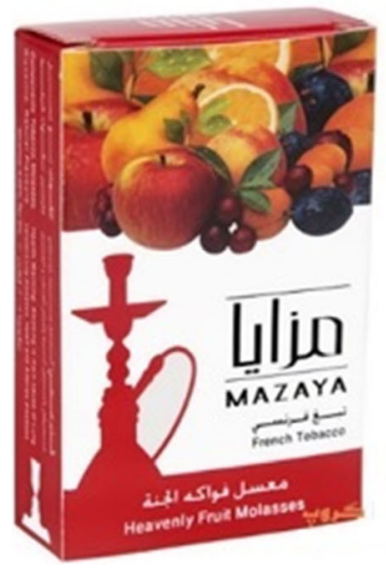

B

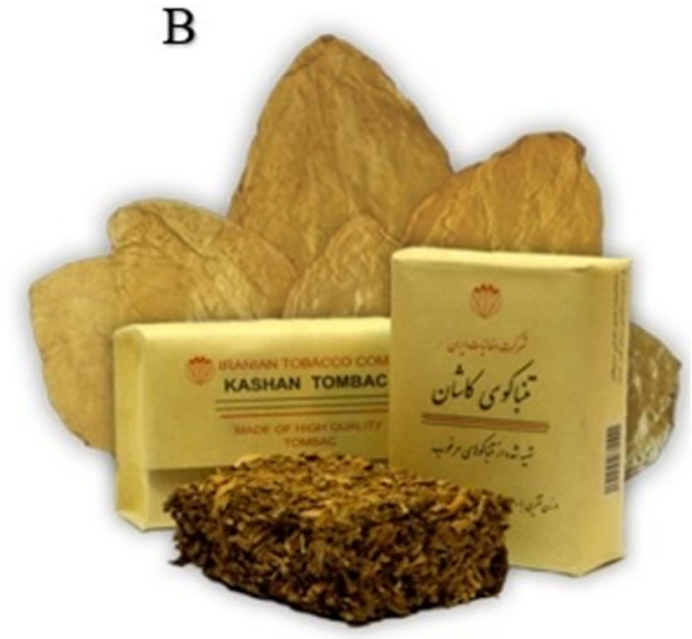




\section{Methods and materials}

\section{Study sample and setting}

Between May $5^{\text {th }}$ and October $30^{\text {th }}, 2019$, a questionnairebased cross-sectional study was conducted in 44 WP-serving venues randomly selected from 15 municipality regions of Tehran, Iran, and 50 venues from 5 municipality regions of Ardabil, Iran. In these cities, three types of WP-serving venues are active (Masjedi et al. 2019). The first venue serves only non-FWT for typically older adult patrons, the second serves FWT-only with younger individuals as typical patrons, and the third venue serves both types of WP flavors (Masjedi et al. 2019). We selected 10-12 WP smokers from each venue using nonprobability (convenience) sampling. Study procedures were identical in both cities. Investigators attended each selected venue during morning/afternoon and evening/night to capture potential smokers. All patrons were approached, and those eligible (i.e., $\geq 18$ years old, willing to participate and sign the written informed consent, not using substances other than tobacco (e.g., opium), smoking FWT-only or non-FWTonly over the past 6 months) were invited to complete the selfadministered paper-and-pencil questionnaire. Of the 1224 people who were approached, 85 declined, 239 were ineligible, and data from 900 participants were included in this study. The questionnaire was in Persian language (translated and back translated by a bilingual [English and Persian] expert) and took approximately $15-20 \mathrm{~min}$. No incentives were provided to participants. The investigator assisted participants who had difficulties reading the questionnaire $(\sim 3 \%)$ by reading each question and noting their response. The study protocol was approved by the Institutional Review Board of Ardabil University of Medical Sciences and Health Services.

\section{Measures}

The questionnaire was developed using measures from existing literature (Akl et al. 2015; Bahelah et al. 2016; Maziak et al. 2015; Ward et al. 2007) on patterns of WP smoking including (i) sociodemographics; (ii) WP smoking behaviors; (iii) beliefs, perceptions, and reasons for WP smoking; (iv) nicotine dependence, and (v) psychological indicators.

i. Sociodemographic variables included age, gender (male/female), education (< high school/ $\geq$ high school), employed (yes/no), physical activity (at least once/week vs no activity), body mass index (BMI; weight in kilograms/height in meters`2), crowding index (defined as the number of co-residents in a dwelling, excluding infants, divided by the number of rooms in the dwelling, excluding the kitchen and bathrooms) (Melki et al. 2004), the number of parents/sibling/friends smoke WP, and presence of $\geq 1$ chronic disease (e.g., heart problem and diabetes).

ii. WP smoking and quitting behavior included age of smoking initiation, the first partner who smoked WP with (alone/friends/family), frequency of WP use in the past 6 months (daily/weekly/monthly), the average quantity of WP use in the past 6 months (number of WPs smoked per month), average usual time spent in a WP smoking ses$\operatorname{sion}(<30 / 30-60 />60 \mathrm{~min})$, attempt to quit $\mathrm{WP}$ in the past year (yes/no), number of attempts to quit in the past year, initiated WP smoking to quit cigarettes (yes/no), and confidence in being able to quit WP at any time. We also collected current (past 30 days) use of cigarettes and non-cigarette (e.g., e-cigarettes) tobacco products.

iii. Attitudes, beliefs, and perceptions included comparative addictiveness and harmfulness of WP smoking with cigarettes (less/equal/more or don't know), ever seen warning messages/labels on WP tobacco packages (yes/no), how often they read warning messages on WP tobacco packages (not at all/sometimes/always), whether smoking WP makes an individual more sociable (yes/ no), smoking WP in Ramadan (the holy month of fasting) (yes/no), sharing WP with others (yes/no), frequency of changing mouthpiece when sharing WP hose with others (never/sometimes/always), allowing son or daughter to smoke WP in the future (yes/no/don't know), and personal reasons for smoking WP (Maziak et al. 2015; WHO 2015).

iv. Nicotine dependence was measured using 4 scales; the Hooked on Nicotine Checklist [HONC; 10 dichotomous (yes/no) items based on the Autonomy Theory of Tobacco Dependence which posits that the appearance of a single symptom of dependence (initial nicotine dependence symptom)] signals a loss of autonomy over tobacco use (DiFranza et al. 2000), the WHO's International Classification of Diseases, 10th Version Criteria for Tobacco Dependence (ICD-10). Criteria for nicotine dependence were assessed using 19 dichotomous (yes/no) items across 6 criteria of nicotine dependence, and attainment of $\geq 3$ criteria over 12 months is the standard threshold for diagnosis of full syndrome of nicotine dependence (DiFranza et al. 2007; WHO 1993). We also used the 13-item Syrian Center for Tobacco Studies13 (SCTS-13), a battery of items addressing behaviors, attitudes, and symptoms related to WP smoking and dependence with response options of "true," "somewhat true," and "not true" and scores of 2,1 , and 0 , respectively. The total scale ranges from 0 to 26 . The higher the total score, the stronger is the nicotine dependence (Alam et al. 2020). Finally, we used a 3 -item scale of the progression of physical dependence on tobacco through stages of wanting, craving, and needing with response options as "describes me not at all," "describes me a 
little," "describes me pretty well," and "describes me very well" (Bahelah et al. 2016; DiFranza et al. 2012). Participants endorsed physical dependence if they selected any response above "describes me not at all" (Bahelah et al. 2016).

v. Psychological indicators were assessed using the Depression Anxiety Stress Scales-21 (DASS-21) which is a self-report instrument containing three 7-item subscales that measure depression, anxiety, and stress experienced during the most recent week (Antony et al. 1998). Participants were asked to score every item on a scale from 0 (never) to 3 (always) yielding a total score ranging from 0 to 21 for each subscale with higher scores indicating greater levels of depression, anxiety, or stress (Ho et al. 2019). This scale was previously validated among the Iranian population (Sahebi et al. 2005).

The consistency of the scales (HONC, ICD10, SCTS-13, and DASS-21) over time (or test-retest reliability) was assessed in a sample of 30 randomly selected WP smokers (15 flavored-only and 15 non-flavored-only WP smokers) after 2-4 weeks by intra-class correlation coefficient (ICC). The Cronbach's $\alpha$ coefficient (reliability) of the Farsi version of the HONC, ICD10, SCTS-13, and DASS-21 was 0.70 or above and considered adequate for our study population (Bartko 1966). These 30 participants were excluded from the main analysis.

\section{Statistical analysis}

The study sample was first categorized by flavor status (FWT vs non FWT). Next, chi-square or Fisher's exact test was used to examine the associations between categorical variables and independent t-test for continuous variables. There were less than $10 \%$ of missing values for our study variables. Since we found no significant group differences between missing and observed values (all $\mathrm{p}>0.05$ ), we considered it missing at random (i.e., missing and observed values had similar distributions) (Bhaskaran and Smeeth 2014). Univariate logistic regression was conducted for all individual variables presented in Table 1. Variables from univariate models that were associated with the outcome (FWT vs non-FWT tobacco use) (at $\mathrm{p}<0.25$ ), along with other variables of known clinical and theoretical relevance (e.g., frequency of use), were entered into a multivariable logistic regression model (Bursac et al. 2008; Mickey and Greenland 1989), which controlled for study site (Tehran or Ardabil), and used backward elimination ( $p<0.05$ required to be retained) to reach the final model (Ward et al. 2007). A multivariable logistic regression model (non-FWT as a reference) was applied to estimate the adjusted odds ratio (AOR) and corresponding $95 \%$ confidence interval (CI). SAS/STATv14.2 (SAS Institute Inc., NC, USA) was used to analyze all data with the significance level set as a two-tailed p-value $<0.05$.

\section{Results and discussion}

Table 1 displays the characteristics of the entire sample $(n=900)$, as well as stratified by type of WP tobacco flavor. Of the 900 participants, 508 (56\%) were FWT-only smokers, and $392(44 \%)$ were non-FWT smokers. More than half of the participants $(n=500)$ were selected from Ardabil city.

\section{Sociodemographic characteristics}

The mean age \pm standard deviation (SD) of participants was $33.4 \pm 13.1$ years, with FWT smokers being younger compared to non-FWT smokers $(26.7 \pm 7.7$ years vs $42.0 \pm 13.6$ years, respectively). The majority of FWT $(77.8 \%)$ and non-FWT $(97.7 \%)$ smokers were male. Non-FWT smokers were less educated, had higher BMI, and were more likely to live in a crowded household. FWT smokers were more likely than non-FWT smokers to report having $\geq 1$ sibling or friends who smoke WP.

\section{Smoking behaviors}

Among all participants, the mean age \pm SD of smoking initiation was 20.2 \pm 7.2 years, with FWT (19.4 \pm 6.9$)$ smokers initiating earlier than non-FWT (21.3 \pm 7.4$)$ smokers. The majority of participants tried their first WP with friends, which was slightly more pronounced for FWT (78\%) compared to nonFWT (72\%) smokers. Although there was no significant difference between the two groups in frequency of use, nonFWT smokers reported smoking an average of $25 \mathrm{WPs} /$ month compared to FWT smokers with $17 \mathrm{WPs} /$ month. The average time spent during the smoking session was mostly between 30 and $60 \mathrm{~min}$, with non-FWT smokers smoking a little longer compared to the FWT group. Although FWT smokers were more interested in quitting in the near future and had tried to quit an average of 3.3 times in the past year, non-FWT smokers were less interested but had an average of 5.6 quit attempts in the past year. More FWT smokers were confident that they could quit at any time compared with nonFWT smokers $(77 \%$ vs $51 \%)$. While $9.8 \%$ of non-FWT smokers were current cigarette users, this estimate was almost doubled among FWT smokers (18.4\%). Compared to FWT smokers, more non-FWT smokers initiated smoking WP to wean off from cigarettes $(21.2 \%$ vs $11.4 \%)$. None of the WP smokers in our sample were currently using tobacco products other than cigarettes. 
Table 1 Characteristics of flavored and non-flavored WP tobacco smokers (N=900)

\begin{tabular}{|c|c|c|c|c|}
\hline Study characteristics & FWT $(\mathrm{n}=508)$ & Non-FWT (n=392) & p-value & Total $(\mathrm{N}=900)$ \\
\hline & $\mathrm{n}(\%) / \mathrm{M} \pm \mathrm{SD}$ & $\mathrm{n}(\%) / \mathrm{M} \pm \mathrm{SD}$ & & $\mathrm{n}(\%) / \mathrm{M} \pm \mathrm{SD}$ \\
\hline \multicolumn{5}{|l|}{ Sociodemographic } \\
\hline Age, $\mathrm{M} \pm \mathrm{SD}$ & $26.7 \pm 7.7$ & $42.0 \pm 13.6$ & $<.001$ & $33.4(13.1)$ \\
\hline Gender (male) & $395(77.8)$ & $383(97.7)$ & $<.001$ & $778(86.4)$ \\
\hline Education (<high school) & $203(40.0)$ & $251(64.0)$ & .001 & $454(50.4)$ \\
\hline Employed (yes) & $256(50.4)$ & $335(85.5)$ & $<.001$ & $591(65.7)$ \\
\hline Physical activity (at least once/week) (yes), n (\%) & $348(68.5)$ & $162(41.3)$ & .001 & $510(56.7)$ \\
\hline BMI (weight/height ${ }^{\wedge}$ ) $\mathrm{M} \pm \mathrm{SD}$ & $24.7 \pm 3.9$ & $26.2 \pm 3.7$ & .001 & $25.5 \pm 3.9$ \\
\hline Crowding & $2.13 \pm 1.1$ & $2.44 \pm 2.1$ & .004 & $2.2 \pm 1.5$ \\
\hline Parents smoke WP (yes) & $201(45.2)$ & $165(42.1)$ & .371 & $366(40.7)$ \\
\hline$\geq 1$ sibling smoke WP (yes) & $253(56.9)$ & $154(39.3)$ & $<.001$ & $407(45.2)$ \\
\hline$\geq 1$ friend smoke WP (yes) & $347(68.3)$ & $231(58.9)$ & .004 & $578(64.2)$ \\
\hline$\geq 1$ chronic disease (yes) & $146(28.7)$ & $129(32.9)$ & .17 & $275(30.6)$ \\
\hline Study site (Ardabil) ${ }^{¥}$ & $242(61.7)$ & $258(50.8)$ & .001 & $500(55.6)$ \\
\hline \multicolumn{5}{|l|}{ Smoking behaviors } \\
\hline Initiation age, $\mathrm{M} \pm \mathrm{SD}$ & $19.4 \pm 6.9$ & $21.3 \pm 7.4$ & $<.001$ & $20.2 \pm 7.2$ \\
\hline \multicolumn{5}{|l|}{ For the first time, who did you smoke WP with? } \\
\hline Alone & $47(9.3)$ & $63(16.1)$ & .008 & $110(12.2)$ \\
\hline Friend(s) & $397(78.1)$ & $282(71.9)$ & & $679(75.4)$ \\
\hline Family member & $64(12.6)$ & $47(12.0)$ & & $111(12.3)$ \\
\hline Own WP device (yes) & $148(37.8)$ & $183(36.0)$ & .593 & $331(36.8)$ \\
\hline \multicolumn{5}{|l|}{ Frequency of use } \\
\hline Monthly & $116(22.8)$ & $102(26.0)$ & .196 & $218(24.2)$ \\
\hline Weekly & $159(31.3)$ & $102(26.0)$ & & $261(29.0)$ \\
\hline Daily & $233(45.9)$ & $188(48.0)$ & & $421(46.8)$ \\
\hline Quantity of use (WPs/month), M \pm SD & $16.9 \pm 17.5$ & $24.7 \pm 26.3$ & $<.001$ & $20.3 \pm 22.1$ \\
\hline \multicolumn{5}{|l|}{ Average usual time during a WP smoking session } \\
\hline$<30 \min$ & $98(19.3)$ & $98(25.0)$ & $<.001$ & $196(21.8)$ \\
\hline $30-60 \mathrm{~min}$ & $361(71.1)$ & $231(58.9)$ & & $592(65.8)$ \\
\hline$>60 \min$ & $49(9.6)$ & $63(16.1)$ & & $112(12.4)$ \\
\hline How many times did you attempt to quit WP smoking in the past year? $\mathrm{M} \pm \mathrm{SD}$ & $3.3 \pm 5.6$ & $5.6 \pm 8.7$ & $<.001$ & $4.3 \pm 7.2$ \\
\hline Currently smoke cigarettes (yes) & $72(18.4)$ & $50(9.8)$ & $<.001$ & $122(13.6)$ \\
\hline Do you want to quit WP smoking in the near future? (yes) & $182(35.8)$ & $114(29.1)$ & .033 & $296(32.9)$ \\
\hline Did you start smoking WP to quit cigarettes? (yes) & $58(11.4)$ & $83(21.2)$ & $<.001$ & $141(15.7)$ \\
\hline \multicolumn{5}{|l|}{ Beliefs and perceptions } \\
\hline \multicolumn{5}{|l|}{ Compared to cigarettes, to what extent is WP harmful? } \\
\hline Less harmful & $168(33.1)$ & $102(26.0)$ & .005 & $270(30.0)$ \\
\hline Equal & $128(25.2)$ & $115(29.3)$ & & $243(27.0)$ \\
\hline More harmful & $161(31.7)$ & $111(28.3)$ & & $272(30.2)$ \\
\hline Don’t know & $51(10.0)$ & $64(16.3)$ & & $115(12.8)$ \\
\hline \multicolumn{5}{|l|}{ Compared to cigarettes, to what extent is WP addictive? } \\
\hline Less addictive & $232(45.7)$ & $155(39.5)$ & .157 & $387(43.0)$ \\
\hline Equally addictive & $142(28.0)$ & $117(29.8)$ & & $259(28.8)$ \\
\hline More addictive & $72(14.2)$ & $55(14.0)$ & & $127(14.1)$ \\
\hline Don’t know & $62(12.2)$ & $65(16.6)$ & & $127(14.1)$ \\
\hline Are you confident that you could quit WP at any time? (yes) & $390(76.8)$ & $200(51.0)$ & .001 & $590(65.6)$ \\
\hline Have you ever seen a warning label on WP tobacco package? (yes) & $357(70.3)$ & $203(51.8)$ & $<.001$ & $560(62.2)$ \\
\hline How often do you read the warning messages on WP tobacco packages? & $235(46.3)$ & $174(44.4)$ & .20 & $409(45.4)$ \\
\hline Not at all & $273(53.7)$ & $218(55.6)$ & .11 & $491(54.6)$ \\
\hline
\end{tabular}


Table 1 (continued)

\begin{tabular}{|c|c|c|c|c|}
\hline Study characteristics & FWT $(\mathrm{n}=508)$ & Non-FWT (n=392) & p-value & Total $(\mathrm{N}=900)$ \\
\hline Sometimes & $183(36.0)$ & $120(30.6)$ & & $303(33.7)$ \\
\hline Always & $52(10.2)$ & $54(13.8)$ & & $106(11.8)$ \\
\hline \multicolumn{5}{|l|}{ Does smoking WP make you more socialized person? } \\
\hline Yes & $292(57.5)$ & $201(51.3)$ & .09 & $493(54.8)$ \\
\hline No & $110(21.7)$ & $87(22.2)$ & & $197(21.9)$ \\
\hline Don’t know & $106(20.9)$ & $104(26.5)$ & & $210(23.3)$ \\
\hline Do you smoke WP in the Ramadan? (yes) & $327(64.4)$ & $304(77.6)$ & $<.001$ & $631(70.1)$ \\
\hline Do you usually share your WP? (yes) & $286(56.3)$ & $125(31.9)$ & $<.001$ & $411(45.7)$ \\
\hline \multicolumn{5}{|c|}{ When you smoke with friends and family HOW often do you change the mouthpiece? } \\
\hline Never & $56(19.6)$ & $35(28.0)$ & .16 & $91(22.1)$ \\
\hline Sometimes & $161(56.3)$ & $62(49.6)$ & & $223(54.3)$ \\
\hline Always & $69(24.1)$ & $28(22.4)$ & & $97(23.6)$ \\
\hline Will you allow your son to smoke WP in the future? (yes ) & $94(18.5)$ & $46(11.7)$ & .005 & $140(15.6)$ \\
\hline Will you allow your daughter to smoke WP in the future? (yes) & $64(12.6)$ & $23(5.9)$ & .001 & $87(9.7)$ \\
\hline \multicolumn{5}{|l|}{ Nicotine dependence and psychological indicators } \\
\hline Initial nicotine dependence symptom (yes) & $442(87.0)$ & $335(85.5)$ & .50 & $777(86.3)$ \\
\hline ICD-10 nicotine dependence (yes) & $379(74.6)$ & $272(69.4)$ & .08 & $651(72.3)$ \\
\hline SCTS-13 M \pm SD * & $12.9 \pm 6.9$ & $13.2 \pm 6.6$ & .67 & $13.03 \pm 6.8$ \\
\hline \multicolumn{5}{|l|}{ Physical dependence $\mathrm{M} \pm \mathrm{SD}$} \\
\hline Wanting & $395(77.8)$ & $298(76.0)$ & .54 & $693(77.0)$ \\
\hline Craving & $355(69.9)$ & $277(70.7)$ & .79 & $632(70.2)$ \\
\hline Needing & $351(69.1)$ & $275(70.2)$ & .73 & $626(69.6)$ \\
\hline \multicolumn{5}{|l|}{ Psychological indicators $\mathrm{M} \pm \mathrm{SD}$} \\
\hline Depression & $3.6 \pm 3.9$ & $4.5 \pm 4.1$ & .01 & $4.0 \pm 3.6$ \\
\hline Anxiety & $3.6 \pm 4.1$ & $4.8 \pm 4.7$ & .004 & $4.2 \pm 3.8$ \\
\hline Stress & $5.1 \pm 4.8$ & $5.8 \pm 4.7$ & .06 & $5.5 \pm 5.1$ \\
\hline
\end{tabular}

Abbreviations: $W P$ waterpipe, $M \pm S D$ mean standard deviation, $B M I$ body mass index, $I C D-10$ International Classification of Diseases, 10 th Version, SCTS-13 Syrian center for Tobacco Studies-13. *The data for SCTS-13 was collected only for the city of Ardabil (n=500). ${ }^{¥}$ Compared to other study site, Tehran

\section{Attitudes, beliefs, and perceptions}

A majority of respondents in both smoking groups believed that WP, compared to cigarettes, is less or equally harmful/or addictive. FWT smokers were more likely than non-FWT to have ever seen warning messages/labels on WP packages ( $70.3 \%$ vs $51.8 \%$, respectively). The two groups did not differ in how often they read WP warning messages, and across groups, only $11 \%$ always did so. More than half of the participants in each group thought that smoking WP makes a person more sociable. About 70\% ( $\mathrm{n}=631)$ of participants smoked WP in Ramadan, with non-FWT smokers having a large proportion compared to FWT smokers. While $56.3 \%$ of FWT smokers usually shared their WP with others, only $32 \%$ of non-FWT smokers did so. Of those who shared their WP with others, it was common that they never $(22 \%)$ or only sometimes $(54 \%)$ changed their mouthpiece. As shown in Fig. 2, entertainment, enjoying WP smoke, and curiosity were cited as the most common reasons for smoking WP for FWT smokers, compared to relieving stress and escaping from loneliness that were the main reasons for smoking WP for nonFWT smokers.

\section{Nicotine dependence measures}

Most respondents (in both FWT and the non-FWT group) experienced initial nicotine dependence symptoms (i.e., at least one of the HONC symptoms) (86.3\%), full ND syndrome $(72.3 \%)$, and physical dependence (wanting: $77.0 \%$, craving: $70.2 \%$, needing: $69.6 \%$ ). The mean SCTS-13 score was slightly higher (though nonsignificant) for non-FWT (13.2 \pm 6.6$)$ compared to FWT

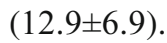


Fig. 2 Reasons for smoking WP among FWT-only and non-FWTonly smokers. Asterisks indicate $\mathrm{p}<0.05$

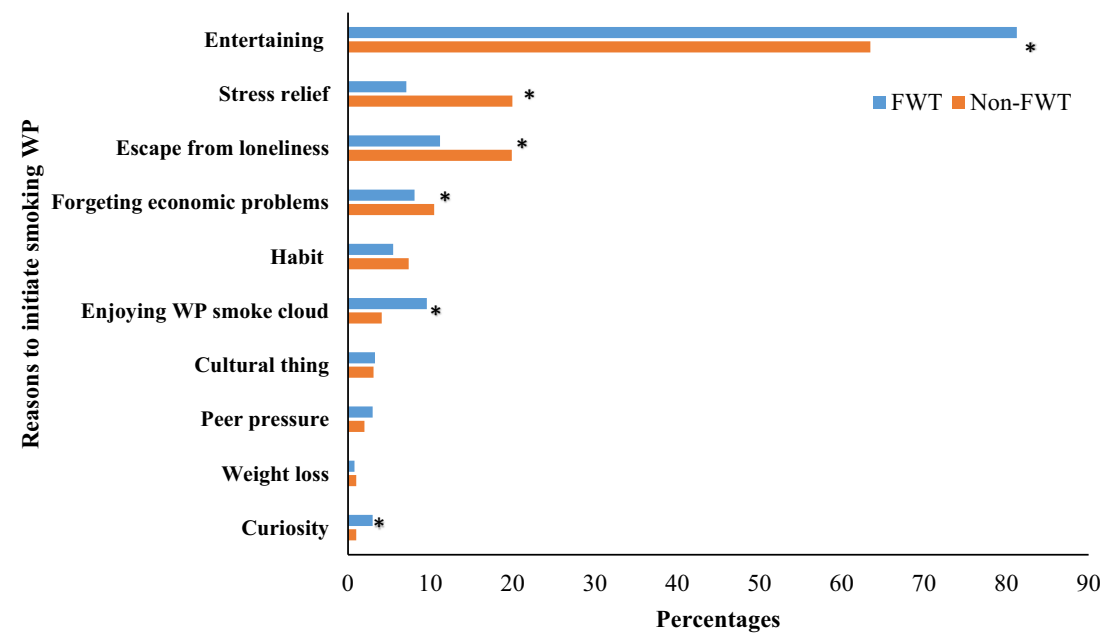

\section{Psychological indicators}

Compared to FWT smokers, non-FWT smokers reported higher depression $(3.6 \pm 3.9$ vs $4.5 \pm 4.1, \mathrm{p}=.01$, respectively) and anxiety (3.6 \pm 4.1 vs $4.8 \pm 4.7, \mathrm{p}=.004$ respectively).

\section{Multivariable logistic regression analysis}

As shown in Table 2, compared to non-FWT smokers, FWT smokers were younger, less likely to be male, to see and read warning messages on WP tobacco packages, and more likely to have one or more sibling who smoke WP, share WP with others, be a current cigarette smoker, and be confident that they can quit WP at any time.

This is the first study to examine individual factors associated with FWT and non-FWT smokers recruited from real-world settings (cafés) in the Middle East. Our findings revealed commonalities and differences between the two groups. While both groups showed similarity in some variables including frequency of use, nicotine dependence, and perceived harm and addictiveness of WP compared to cigarette, they significantly differed in age, sex, sibling WP smoking, WP sharing behavior, exposure to health warning messages on WP tobacco packages, current use of cigarettes, and confidence in quitting WP. These findings can help in developing WP tobacco-specific policies and cessation interventions among WP smokers in Middle Eastern countries such as Iran, where both forms of WP tobacco smoking (FWT and non-FWT) are common.

There is well-developed literature showing that WP tobacco flavorings are the main attribute that encourages young people to initiate WP smoking and engage in continued WP use (Ben Taleb et al. 2019a; Initiative 2018; Odani et al. 2020). Similarly, in our study, the mean age of smoking initiation among FWT smokers was younger than their non-FWT counterparts, reflecting the attractiveness of flavorings for younger people, as well as its increased popularity among women. Our findings add to the existing evidence base (Ben Taleb et al. 2019a) that limiting flavors could have substantial effects on reducing the WP smoking rate among young people and could help keep the prevalence of female tobacco use low in Middle East countries like Iran (Baheiraei et al. 2012; Ebrahimi Kalan and Ben Taleb 2018).
Table 2 Multivariable correlates of flavored waterpipe tobacco users relative to unflavored waterpipe tobacco users

\begin{tabular}{llll}
\hline Variables & AOR & (95\%CI) & P-value \\
\hline Age & 0.88 & $0.87-0.90$ & $<.0001$ \\
Male vs female & 0.16 & $0.07-0.34$ & $<.0001$ \\
$\geq 1$ Siblings who smoke WP (yes vs no) & 1.54 & $1.06-2.24$ & 0.02 \\
Share WP (yes vs no) & 2.52 & $1.68-3.77$ & 0.0004 \\
Have seen HWL on WP package (yes vs no) & 0.40 & $0.27-0.60$ & $<.0001$ \\
Read HWL on WP packages (sometimes vs not at all) & 0.78 & $0.51-1.19$ & 0.44 \\
Read HWL on WP packages (always vs not at all) & 0.44 & $0.24-0.80$ & 0.015 \\
Current cigarette smoker (yes vs no) & 2.05 & $1.23-3.42$ & 0.005 \\
Are you confident that you could quit WP at any time? (yes vs no) & 3.64 & $2.45-5.39$ & $<.001$ \\
\hline
\end{tabular}

Note. $A O R$ adjusted odds ratio, $C I$ confidence interval, $H W L$ health warning labels. *Coded $0=$ non-flavored and 1=flavored WP tobacco users. Multivariable analysis also included site of study (Ardabil vs Tehran) 
Numerous studies (Daniels and Roman 2013; Fielder et al. 2012; Joveyni et al. 2012; Khalil et al. 2013; Sabahy et al. 2011) have emphasized social motivations for WP use, including having fun, socializing, spending time with friends, curiosity, having a new experience, peer pressure, and feeling of calmness and reduction of stress and fatigue. In our study, while both smoking groups cited social interaction as a major reason to smoke WP, it was significantly higher for FWT smokers. FWT smokers were more likely to have a sibling who smoked WP and were more likely to cite enjoying the WP smoke cloud and curiosity as main reasons for smoking WP. Alternatively, non-FWT users reported smoking WP to reduce stress, escape loneliness, and forget economic problems. Correspondingly, non-FWT smokers were less educated and reported higher levels of stress, anxiety, and depression indicating that they could be using WP as a stress-coping mechanism.

Another indicator of differences in the social motivation in WP use between FWT and non-FWT users can be seen in relation to the likelihood of WP sharing. Our results indicate that a majority (56.3\%) of FWT smokers share their WP with others, consistent with behaviors found in previous studies conducted in EMR (Dar-Odeh et al. 2010; Farah et al. 2020; Maziak et al. 2004b) and the USA (American Lung Association 2012; Ben Taleb et al. 2019a; Ward et al. 2007). However, in contrast to existing data on FWT users, our study found that non-FWT smokers were less likely to share their WP (31.9\%). Unfortunately, even with the recent development and current use of disposable mouthpieces in WPserving venues (Salloum et al. 2016), only $24.1 \%$ of FWT smokers and $22.4 \%$ of non-FWT smokers in our sample "always" use the personal mouthpiece. The practice of replacing the mouthpiece when sharing may be frowned upon in many Middle Eastern countries such as Iran (Martinasek et al. 2011; Maziak et al. 2004b) where sharing represents a cultural manifestation of hospitality and generosity (Martinasek et al. 2011). Notably, this is an especially critical time for interventions aimed at limiting WP sharing as it can result in the spread of viruses and bacteria transmitted through oral secretions, including COVID-19 that is mainly spread through respiratory droplets (Altindis et al. 2020; Martinasek et al. 2011; Munckhof et al. 2003; Salem et al. 1973; Salem and Sami 1974; Yadav and Thakur 2000). Adding to this concern, previous environmental exposure studies have shown significantly higher concentrations of particulate matter in the indoor air of WP cafés serving FWT, as compared with those serving non-FWT (Naddafi et al. 2019b). These findings, together with the emergence of the COVID-19 pandemic (Ebrahimi Kalan M 2020), make it crucial to enhance public health oversight aimed to increase sanitation of WP devices and adequate cleaning of WPs which could help to prevent the spread of infectious diseases such as COVID-19, particularly among FWT smokers.
Unlike warning labels on cigarette packages, past data suggest that having warning labels on WP tobacco packages may not be an adequate way of conveying health warning message (CDC 2011). Our study found that FWT smokers were less likely to see and read health warning messages on WP tobacco packages compared to non-FWT smokers. This difference could be related to owning WP and preparing WP at home which increase the exposure to tobacco package compared to café environments where smokers are only exposed to the device rather than tobacco packages (Heydari et al. 2018; Maziak et al. 2004c; Nakkash and Khalil 2010). However, in our study, almost equal proportions of FWT and nonFWT smokers reported having their own WP (36\% vs $37.8 \%$ ) suggesting there are other reasons for paying attention to warning messages that need to be explored in future studies.

Previous studies showed that a sizable number of WP smokers are confident that they could quit using WP whenever they want (Ward et al. 2007; Ward et al. 2005). This attitude was also observed in our sample, which was more pronounced among FWT smokers than non-FWT. Consistent with the literature (Asfar et al. 2005; Maziak et al. 2004a; Ward et al. 2007; Ward et al. 2005), the majority of WP smokers in our study believed WP smoking was less addictive than cigarettes, a belief that motivated nearly a quarter of non-FWT smokers to switch from cigarettes to WP. The finding that more than $70 \%$ of our sample attained full ND syndrome over the past 12 months is not surprising since initial dependence symptoms and full nicotine dependence syndrome can develop sooner after starting to smoke and progress more rapidly from a young age among WP smokers as compared with cigarette smokers (Ebrahimi Kalan et al. 2020a, b). Taken together, WP-specific targeted interventions are warranted to raise awareness about the potential harmfulness and addictiveness of this smoking mode, prevent the occurrence of nicotine dependence symptoms, and promote cessation, especially among FWT smokers who are younger, at greater risk of being hooked on nicotine, less likely to be interested in quitting, and comprise the majority of the WP smokers around the globe. However, our results also indicate that non-FWT smokers require enhanced cessation support given their typically longer history of WP use and multiple unsuccessful quit attempts.

The results of our study must be interpreted in the context of several limitations. First, the study was conducted in only two large cities in Iran; thus, its results may not be generalizable to other parts of Iran and beyond. Even though participants were sampled using a convenience approach, the sites within the cities were selected randomly, therefore minimizing the generalizability gap for the participating areas. Second, data were self-reported and might be subject to recall and response bias; nevertheless, self-report data collection is a valid measure of behavioral research including smoking characteristics (Patrick et al. 1994). 


\section{Conclusions}

This study compared the characteristics of FWT and nonFWT smokers who were recruited in a real-world setting (cafés) in two cities in Iran. Our findings showed that FWT smokers (compared to non-FWT) tend to be younger and have sibling(s) who smoke WP, share their WP with others, smoke cigarettes, and report confidence in quitting at any time. On the other hand, they were less likely to have seen or read health warning messages on WP tobacco packages relative to non-FTW smokers. For both groups, the most cited reason for smoking WP was entertainment, followed by stress relief for non-FWT smokers and the escape from loneliness for FWT smokers. Observed differences between FWT and non-FWT smokers in reasons to smoke WP and their associated behaviors call for more targeted WP prevention, control, and cessation interventions in the Middle East. Our findings underscore the need for considering flavored and non-flavored tobacco use in developing and implementing tobacco prevention programs.

\section{Recommendations on WP-specific policy and cessation}

Raising awareness regarding the harmful and addictive effects of WP tobacco smoking and developing and implementing graphic health warning labels on WP devices is particularly crucial to curb the uptake and spread of FWT smoking.

Most importantly, prevention and cessation intervention programs should be tailored based on the age of the targeted population. For example, the role of flavor in masking the harms associated with FWT smoking, nicotine dependence, and the risk of cross infection should be emphasized in campaigns targeted toward the youth who often attracted to use FWT and smoke with a group of friends.

One the other hand, informative cessation programs that are focused on correcting misconceptions regarding the reduced harm of WP smoking in comparison with cigarette and supplemented with mental health counseling is an important approach for non-FWT smokers who are more likely to switch from cigarette to non-FWT and smoke WP to cope with stress.

Accordingly, finding from this study will help in developing comprehensive WP tobacco-specific policy and cessation interventions among WP smokers in the Middle Eastern countries such as Iran, where both forms of tobacco smoking (FWT and non-FWT) are common.

Availability of data and materials The data used and analyzed during the current study are available from the corresponding author upon reasonable request.
Author contribution MEK and MFZ conceptualized and designed the study. MFZ obtained the data. MEK and ZB analyzed the data. MEK and MFZ wrote the first draft of the manuscript. MA, ZBT, DA, ZB, $\mathrm{KDW}, \mathrm{COC}, \mathrm{RB}$, and HLW provided critical intellectual feedback to the manuscript. All authors read and approved the final manuscript.

Funding This research work was financially supported by the Ardabil University of Medical Sciences; we gratefully acknowledge them.

\section{Declarations}

Ethical consideration The protocol was approved by the Institutional Review Board of Ardabil University of Medical Sciences (Approval ID: IR.ARUMS.REC.1398.310).

Consent to participate Not applicable.

Consent to publish All the authors agreed to publish the data in this journal.

Conflict of interest The authors declare no competing interests.

\section{References}

Akl EA, Ward KD, Bteddini D, Khaliel R, Alexander AC, Lotfi T, Alaouie H, Afifi RA (2015) The allure of the waterpipe: a narrative review of factors affecting the epidemic rise in waterpipe smoking among young persons globally. The allure of the waterpipe: a narrative review of factors affecting the epidemic rise in waterpipe smoking among young persons globally Tobacco Control 24:113i21. https://doi.org/10.1136/tobaccocontrol-2014-051906

Alam MM, Ward KD, Bahelah R, Kalan ME, Asfar T, Eissenberg T, Maziak W (2020) The Syrian Center for Tobacco Studies-13 (SCTS-13): psychometric evaluation of a waterpipe-specific nicotine dependence instrument. Drug Alcohol Depend 215:108192. https://doi.org/10.1016/j.drugalcdep.2020.108192

Altindis M, Koroglu M, Demiray T et al (2020) Microbial contamination and infection risks of narghile besides hazards of tobacco. Cent Eur J Public Health 28:74-78. https://doi.org/10.21101/cejph.a5814

Alvur MT, Cinar N, Akduran F, Dede C (2014) Fallacies about water pipe use in Turkish university students - what might be the consequences? Asian Pacific journal of cancer prevention : APJCP 15: 1977-1980. https://doi.org/10.7314/apjcp.2014.15.5.1977

American Lung Association (2012) Tobacco policy trend alert, an emerging deadly trend: waterpipe tobacco use:2007

Antony MM, Bieling PJ, Cox BJ et al (1998) Psychometric properties of the 42 -item and 21 -item versions of the depression anxiety stress scales in clinical groups and a community sample. 10:176

Asfar T, Ward KD, Eissenberg T, Maziak W (2005) Comparison of patterns of use, beliefs, and attitudes related to waterpipe between beginning and established smokers. BMC Public Health 5:19-19. https://doi.org/10.1186/1471-2458-5-19

Baheiraei A, Mirghafourvand M, Nedjat S et al (2012) Prevalence of water pipe use and its correlates in iranian women of reproductive age in tehran: a population-based study medical principles and practice. 21:340-344. https://doi.org/10.1159/000336583

Bahelah R, DiFranza JR, Fouad FM et al (2016) Early symptoms of nicotine dependence among adolescent waterpipe smokers Tobacco Control. 25:e127-e134. https://doi.org/10.1136/ tobaccocontrol-2015-052809 
Bartko JJ (1966) The intraclass correlation coefficient as a measure of reliability. Psychol Rep 19:3-11. https://doi.org/10.2466/pr0.1966. 19.1.3

Ben Taleb Z, Vargas-Rivera M, Ebrahimi Kalan M et al. (2019a) The effect of flavored and non-flavored tobacco on subjective experience, topography and toxicant exposure among waterpipe smokers Tobacco Control tobaccocontrol-2019-054972

Ben Taleb Z, Vargas M, Ebrahimi Kalan M, Breland A, Eissenberg T, Brown D, Maziak W (2019b) The effect of flavoured and nonflavoured tobacco on subjective experience, topography and toxicant exposure among waterpipe smokers Tobacco Control: tobaccocontrol-2019-054972. 29:s72-s79. https://doi.org/10.1136/ tobaccocontrol-2019-054972

Bhaskaran K, Smeeth L (2014) What is the difference between missing completely at random and missing at random? Int J Epidemiol 43: 1336-1339. https://doi.org/10.1093/ije/dyu080

Bou Fakhreddine HM, Kanj AN, Kanj NA (2014) The growing epidemic of water pipe smoking: health effects and future needs. Respir Med 108:1241-1253. https://doi.org/10.1016/j.rmed.2014.07.014

Bursac Z, Gauss CH, Williams DK, Hosmer DW (2008) Purposeful selection of variables in logistic regression. Source Code Biol Med 3:17. https://doi.org/10.1186/1751-0473-3-17

CDC (2011) Centers for Disease Control and Prevention. Cigarette package health warnings and interest in quitting smoking - 14 countries, 2008-2010 MMWR Morb Mortal Wkly Rep 60:645-651

Daniels KE, Roman NV (2013) A descriptive study of the perceptions and behaviors of waterpipe use by university students in the Western Cape. South Africa Tob Induc Dis 11:4. https://doi.org/10.1186/ 1617-9625-11-4

Dar-Odeh NS, Bakri FG, Al-Omiri MK et al (2010) Narghile (water pipe) smoking among university students in Jordan: prevalence, pattern and beliefs. Harm Reduct J 7:10. https://doi.org/10.1186/14777517-7-10

DiFranza JR, Rigotti NA, AD MN et al (2000) Initial symptoms of nicotine dependence in adolescents. Tob Control 9:313-319. https:// doi.org/10.1136/tc.9.3.313

DiFranza JR, Savageau JA, Fletcher K et al (2007) Susceptibility to nicotine dependence: the development and assessment of nicotine dependence in youth 2 study. Pediatrics 120:e974-e983. https://doi. org/10.1542/peds.2007-0027

DiFranza JR, Wellman RJ, Savageau JA (2012) Does progression through the stages of physical addiction indicate increasing overall addiction to tobacco? Psychopharmacology 219:815-822. https:// doi.org/10.1007/s00213-011-2411-4

Ebrahimi Kalan M, Ben Taleb Z (2018) Waterpipe tobacco smoking: a reality or hidden iceberg for Iranian women. Health Promot Perspect 8:252-254. https://doi.org/10.15171/hpp.2018.35

Ebrahimi Kalan M, Behaleh R, Difranza JR et al (2020a) natural course of nicotine dependence among adolescent waterpipe and cigarette smokers. J Adolesc Health 67:859-867. https://doi.org/10.1016/j. jadohealth.2020.04.030

Ebrahimi Kalan M BTZ, Fazlzadeh M, Ward KD, Maziak W. (2020b) Waterpipe tobacco smoking: a potential conduit of COVID-19.

El-Zaatari ZM, Chami HA, Zaatari GS (2015) Health effects associated with waterpipe smoking. Tob Control 24:i31-i43. https://doi.org/10. 1136/tobaccocontrol-2014-051908

Farah R, Haddad C, Sacre H et al (2020) Knowledge and attitude toward waterpipe smoking: scale validation and correlates in the Lebanese adult population. Environ Sci Pollut Res 27:31250-31258. https:// doi.org/10.1007/s11356-020-09425-5

Fazlzadeh M, Rostami R, Hazrati S et al (2015) Concentrations of carbon monoxide in indoor and outdoor air of Ghalyun cafes. Atmospheric Pollution Research 6:550-555. https://doi.org/10.5094/APR.2015. 061

Fielder RL, Carey KB, Carey MP (2012) Prevalence, frequency, and initiation of hookah tobacco smoking among first-year female college students: a one-year longitudinal study. Addict Behav 37: 221-224. https://doi.org/10.1016/j.addbeh.2011.10.001

Hawari FI, Obeidat NA, Ayub $\mathrm{H}$ et al (2013) The acute effects of waterpipe smoking on lung function and exercise capacity in a pilot study of healthy participants. Inhal Toxicol 25:492-497. https://doi. org/10.3109/08958378.2013.806613

Heydari G, Zaatari G, Al-Lawati JA et al. (2018) MPOWER, needs and challenges: trends in the implementation of the WHO FCTC in the Eastern Mediterranean Region 24

Heydari G, Taghizdeh F, Fazlzadeh M, Jafari AJ, Asadgol Z, Mehrizi EA, Moradi M, Arfaeinia H (2019) Levels and health risk assessments of particulate matters (PM 2.5 and PM 10 ) in indoor/outdoor air of waterpipe cafés in Tehran, Iran. Environ Sci Pollut Res 26:72057215. https://doi.org/10.1007/s11356-019-04202-5

Ho C, Tan E, Ho R et al (2019) Relationship of anxiety and depression with respiratory symptoms: comparison between depressed and non-depressed smokers in Singapore. Int J Environ Res Public Health 16. https://doi.org/10.3390/ijerph16010163

Initiative T (2018) flavored tobacco use among youth and young adults. https://truthinitiative.org/news/flavored-tobacco-use-among-youthand-young-adults

Jawad M, Roderick P (2017) Integrating the impact of cigarette and waterpipe tobacco use among adolescents in the Eastern Mediterranean Region: a cross-sectional, population-level model of toxicant exposure. Tob Control 26:323. https://doi.org/10.1136/ tobaccocontrol-2015-052777

Joveyni H, Dehdari T, Gohari Mr et al. (2012) The survey of attitudes, subjective norms and perceived behavioral control of college students about hookah smoking cessation

Khalil J, Afifi R, Fouad FM et al (2013) Women and waterpipe tobacco smoking in the eastern mediterranean region: allure or offensiveness. Women Health 53:100-116. https://doi.org/10.1080/ 03630242.2012 .753978

Leavens EL, Driskill LM, Molina N, Eissenberg T, Shihadeh A, Brett EI, Floyd E, Wagener TL (2018) Comparison of a preferred versus nonpreferred waterpipe tobacco flavour: subjective experience, smoking behaviour and toxicant exposure. Tob Control 27:319-324. https:// doi.org/10.1136/tobaccocontrol-2016-053344

Mamtani R, Cheema S, Sheikh J et al (2017) Cancer risk in waterpipe smokers: a meta-analysis. International journal of public health 62 : 73-83. https://doi.org/10.1007/s00038-016-0856-2

Martinasek MP, McDermott RJ, Martini L (2011) Waterpipe (Hookah) tobacco smoking among youth current problems in pediatric and adolescent health care. 41:34-57. https://doi.org/10.1016/j.cppeds. 2010.10.001

Masjedi MR, Taghizadeh F, Hamzehali S, Ghaffari S, Fazlzadeh M, Jafari AJ, Niazi S, Mehrizi EA, Moradi M, Pasalari H, Arfaeinia H (2019) Air pollutants associated with smoking in indoor/outdoor of waterpipe cafés in Tehran. Iran: concentrations, affecting factors and health risk assessment Scientific reports 9:3110-3110. https://doi. org/10.1038/s41598-019-39684-3

Maziak W, Eissenberg T, Rastam S et al (2004a) Beliefs and attitudes related to narghile (waterpipe) smoking among university students in Syria. Ann Epidemiol 14:646-654. https://doi.org/10.1016/j. annepidem.2003.11.003

Maziak W, Fouad F, Asfar T et al (2004b) Prevalence and characteristics of narghile smoking among university students in Syria. 8:882-889

Maziak W, Ward KD, Afifi Soweid RA et al (2004c) Tobacco smoking using a waterpipe: a re-emerging strain in a global epidemic. Tob Control 13:327-333. https://doi.org/10.1136/tc.2004.008169

Maziak W, Taleb ZB, Bahelah R, Islam F, Jaber R, Auf R, Salloum RG (2015) The global epidemiology of waterpipe smoking. Tob Control 24:i3-i12. https://doi.org/10.1136/tobaccocontrol-2014-051903

Melki IS, Beydoun HA, Khogali M et al (2004) Household crowding index: a correlate of socioeconomic status and inter-pregnancy 
spacing in an urban setting. J Epidemiol Community Health 58: 476-480. https://doi.org/10.1136/jech.2003.012690

Mickey RM, Greenland S (1989) The impact of confounder selection criteria on effect estimation. Am J Epidemiol 129:125-137. https:// doi.org/10.1093/oxfordjournals.aje.a115101

Munckhof WJ, Konstantinos A, Wamsley M et al (2003) A cluster of tuberculosis associated with use of a marijuana water pipe. Int $\mathrm{J}$ Tuberc Lung Dis 7:860-865

Naddafi K, Nabizadeh R, Rostami R, Ghaffari HR, Fazlzadeh M (2019a) Formaldehyde and acetaldehyde in the indoor air of waterpipe cafés: measuring exposures and assessing health effects. Build Environ: 165. https://doi.org/10.1016/j.buildenv.2019.106392

Naddafi K, Nabizadeh R, Rostamy R, Ebrahimi Kalan M, Hassanvand MS, Fazlzadeh M (2019b) Indoor air quality in waterpipe cafés: exposure level to particulate matter. Environ Sci Pollut Res 26: 26605-26616. https://doi.org/10.1007/s11356-019-05546-8

Nakkash R, Khalil J (2010) Health warning labelling practices on narghile (shisha, hookah) waterpipe tobacco products and related accessories. Tob Control 19:235-239. https://doi.org/10.1136/tc.2009. 031773

Odani S, Armour B, Agaku IT (2020) Flavored tobacco product use and its association with indicators of tobacco dependence among US adults, 2014-2015. Nicotine Tob Res 22:1004-1015. https://doi. org/10.1093/ntr/ntz092

Patrick DL, Cheadle A, Thompson DC, Diehr P, Koepsell T, Kinne S (1994) The validity of self-reported smoking: a review and metaanalysis. Am J Public Health:84-1093. https://doi.org/10.2105/ajph. 84.7.1086

Qasim H, Alarabi AB, Alzoubi KH et al (2019) The effects of hookah/ waterpipe smoking on general health and the cardiovascular system. Environ Health Prev Med 24:58-58. https://doi.org/10.1186/ s12199-019-0811-y

Rostami R, Zarei A, Saranjam B, Ghaffari HR, Hazrati S, Poureshg Y, Fazlzadeh M (2019) Exposure and risk assessment of PAHs in indoor air of waterpipe cafés in Ardebil. Iran Build Environ 155:4757. https://doi.org/10.1016/j.buildenv.2019.03.031

Rostami R, Naddafi K, Arfaeinia H et al (2020) The effects of ventilation and building characteristics on indoor air quality in waterpipe cafés. J Exp Sci Environ Epidem 30:805-813. https://doi.org/10.1038/ s41370-020-0240-4

Rostami R, Kalan ME, Ghaffari HR, Saranjam B, Ward KD, Ghobadi H, Poureshgh Y, Fazlzadeh M (2021) Characteristics and health risk assessment of heavy metals in indoor air of waterpipe cafés. Build Environ 190:107557. https://doi.org/10.1016/j.buildenv.2020. 107557

Sabahy AR, Divsalar K, Bahreinifar S et al (2011) Waterpipe tobacco use among Iranian university students: correlates and perceived reasons for use. Intern J Tuberculosis and Lung Disease 15:844-847. https:// doi.org/10.5588/ijtld.10.0744

Sahebi A, Asghari MJ, RSJIP S (2005) Validation of depression anxiety and stress scale (DASS-21) for an Iranian population. 4:299-313

Salem E, Sami A Studies on pulmonary manifestations of goza smokers. In: Chest, 1974. vol 5. AMER COLL CHEST PHYSICIANS 3300 DUNDEE ROAD, NORTHBROOK, IL 60062-2348, pp 599-599

Salem E, Abdel Hakim M, AJEJCDT H (1973) Goza versus cigarette smoking among patients with pulmonary disease. 16:9

Salloum RG, Asfar T, Maziak W (2016) Toward a regulatory framework for the waterpipe. Am J Public Health 106:1773-1777. https://doi. org/10.2105/AJPH.2016.303322

Villanti AC, Johnson AL, Ambrose BK, Cummings KM, Stanton CA, Rose SW, Feirman SP, Tworek C, Glasser AM, Pearson JL, Cohn AM, Conway KP, Niaura RS, Bansal-Travers M, Hyland A (2017) Flavored tobacco product use in youth and adults: findings from the first wave of the PATH study (2013-2014). Am J Prev Med 53:139 151. https://doi.org/10.1016/j.amepre.2017.01.026

Ward KD, Hammal F, VanderWeg MW, Eissenberg T, Asfar T, Rastam S, Maziak W (2005) Are waterpipe users interested in quitting? Nicotine \& tobacco research : official journal of the Society for Research on Nicotine and Tobacco 7:149-156. https://doi.org/10. 1080/14622200412331328402

Ward KD, Eissenberg T, Gray JN, Srinivas V, Wilson N, Maziak W (2007) Characteristics of U.S. waterpipe users: a preliminary report Nicotine \& tobacco research : official. journal of the Society for Research on Nicotine and Tobacco 9:1339-1346. https://doi.org/ 10.1080/14622200701705019

WHO (1993) World Health Organization, The ICD-10 Classification of Mental and Behavioural Disorders: Diagnostic criteria for research. Switzerland, Geneva

WHO (2015) World Health Organization Study Group on Tobacco Product Regulation. Advisory note: waterpipe tobacco smoking: health effects, research needs and recommended actions by regulators. 2nd edn.,

World Health Organization (2019) WHO REPORT ON THE GLOBAL TOBACCO EPIDEMIC, 2019. Offer help to quit tobacco use. https://apps.who.int/iris/bitstream/handle/10665/326043/ 9789241516204-eng.pdf?ua=1

Yadav JS, Thakur S (2000) Genetic risk assessment in hookah smokers. Cytobios 101:101-113

Publisher's note Springer Nature remains neutral with regard to jurisdictional claims in published maps and institutional affiliations. 